\title{
Design, Development, Optimization and Evaluation of Ranolazine Extended Release Tablets
}

\author{
(D) Raghavendra Kumar GUNDA ${ }^{1 *}$, (D) Prasada Rao MANCHINENI², (D) Dhachinamoorthi DURAISWAMY3, (D) Koteswara Rao GSN4 \\ 1Vignan's Foundation for Science, Technology and Research (Deemed to be University), Faculty of Pharmacy, Department of Pharmaceutical Sciences, \\ Andhra Pradesh, India \\ 2M.A.M College of Pharmacy, Department of Pharmaceutical Analysis, Andhra Pradesh, India \\ ${ }^{3} \mathrm{Q} I S$ College of Pharmacy, Department of Pharmaceutics, Andhra Pradesh, India \\ 4KL College of Pharmacy, Koneru Lakshmaiah Education Foundation (Deemed to be University), Department of Pharmaceutics, Andhra Pradesh, India
}

\begin{abstract}
Objectives: The objective of the current study was to develop an extended release (XR) tablet formulation for ranolazine using Eudragit $L$ 100-55 and hydroxypropylmethylcellulose (HPMC) K100M in an appropriate composition. Ranolazine, an anti-anginal agent, is mainly used for treating chronic stable angina pectoris. The main advantage of this drug that it exhibits anti-ischemic effect, which was not influenced by either blood pressure or heart rate.

Materials and Methods: XR tablets of ranolazine were prepared using variable amounts of Eudragit L 100-55 and HPMC K100M in various proportions as per $3^{2}$ factorial design by direct compression technique. The amount of polymers with desired sustained drug release was labeled as factors. On other hand, time taken for drug dissolution was labeled as responses $\left(t_{10 \%}, t_{50 \%}, t_{75 \%}, t_{90 \%}\right)$.

Results: Nine formulations were obtained as per design, developed, and evaluated for quality control parameters. The obtained results clear that all formulations pass the compendial limits. Data obtained from the dissolution study fitted well to kinetic modeling and kinetic parameters were determined. Polynomial equations were derived for responses and checked for validity.

Conclusion: $R F_{5}$ composed of 31.25 mg of Eudragit $L 100-55$ and 31.25 mg of HPMC K100M, is the best formulation showing similarity $f_{2}$ : 85.78 , $f_{1}$ : 2.32 with the marketed product (RANEXA). Formulation $\mathrm{RF}_{5}$ follows zero order, whereas the release mechanism was found to be non-fickian type $(n=0.65)$.
\end{abstract}

Key words: Ranolazine, extended release, Eudragit L 100-55, HPMC K100M, $3^{2}$ factorial design, non-fickian diffusion

\section{INTRODUCTION}

Extended release (XR) formulations deliver effective plasma concentrations of the drug for desired prolonged period. They improve patient compliance by reducing the repeated administration of dosage regime. They also offer improved in vivo clinical performance (good clinical outcome).,2

The popularly used symbols for extended release are extra long/ extra large; long acting; XR. They show a 2 -fold reduction in the dosing frequency and maintains steady state plasma profile. ${ }^{3}$ There are many challenges for formulation of prolonged release dosage forms in a controlled manner for obtaining absorption and improved bioavailability. 4,5
Ranolazine is an anti-anginal agent, which is a piperazine acetamide derivative. It acts by partial inhibition of fatty acid oxidase that increases the adenosine triphosphate production from glucose, thereby improves the functionality of the myocardium. Hence, it exhibits anti-ischemic action, independent of hemodynamics such as blood pressure and heart rate. There will be no significant effect of its effectiveness by the above-mentioned factors and other co-morbidities. Due to this advantage, it is employed as effective anti-ischemic or antiangina agents for treating unstable chronic angina pectoris (exercise induced variant), myocardial infarction, and cardiac arrhythmias. $^{6-8}$ 
Ranolazine belongs to biopharmaceutical classification system class-II agent. It shows an erratic (variant) and extensive first pass effect. Solubility was found to be relatively high at acidic $\mathrm{pH}$ (stomach). The half-life is around $2.5 \mathrm{~h}(2.5 \pm 0.5)$. Hence, selection of release rate modifiers is a challenging task for researchers. ${ }^{9-14}$

The current study focuses on, development of $X R$ tablets for ranolazine with the help of polymers Eudragit $L$ 10055 (partially neutralized $\mathrm{pH}$ dependent polymer) along with hydroxypropylmethylcellulose (HPMC) K100M (pH independent polymer).

The application of polynomial based response surface morphology (RSM) occupies a major volume in case of pharmaceutical product development. The most widely used methods in the above-mentioned category as follows factorial design $\left(2^{3}, 3^{2}, 3^{3}\right)$, central composite design, Box-Behnken design. 15,16

The manufacture of tablets processed using direct compression technique is a frequent method, observed in many pharmaceutical industries. ${ }^{17}$

A two factors, 3-levels study ( $3^{2}$ factorial design) was used to observe the combination effect of both polymers (Eudragit $L$ 100-55; HPMC K100M) on the drug release from the formulation (to see the effect of factors on the responses), ${ }^{18}$ which may improve patient compliance by using enhanced clinical efficiency.

\section{MATERIALS AND METHODS}

\section{Materials}

A gift sample of ranolazine was procured from Mahys Pharma, Solan, India. Eudragit L 100-55 was obtained from KU Pharma Pvt Ltd., while bartoli HPMC K100M was gifted from QIM Chemicals, Guntur. All other excipients were obtained from S.D. Fine Chem., Ltd. Mumbai, India.

Design and development of extended release tablets for ranolazine

Quantities required for the Eudragit L 100-55 and HPMC K100M for developing ranolazine $X R$ tablets were chosen as factors $\left(X_{1}, X_{2}\right.$ respectively). Time to obtain dissolution was chosen as responses $\left(t_{10 \%}, t_{50 \%}, t_{75 \%}, t_{90 \%}\right)$. RSM prediction equations (polynomial) were derived for responses according to linear stepwise backward regression technique. ${ }^{19}$

The 3 levels of $X_{1}$ (Eudragit L 100-55) were 3.75\%, 6.25\%, 8.75\%. Three levels of $X_{2}$ (HPMC K100M) were 3.75\%, 6.25\%, 8.75\% (\% with respect to weight of active ingredient). Nine ranolazine XR tablet formulations were designed using selected combinations of $X_{1}, X_{2}$ and checked for selecting optimum composition required to meet the primary objective of the study.

\section{Preparation of ranolazine extended release tablets}

A 3 level, 2-factor design was used for this research work. The amount of Eudragit $L 100-55$ chosen as $X_{1}$ and amount of HPMC K100M chosen as $X_{2}$ shown in Table 1 . Three levels of both factors chosen indicated as $-1=3.75 \% ; 0=6.25 \% ;+1=8.75 \%$.
$\mathrm{XR}$ tablets for ranolazine were obtained using the direct compression method. Each tablet contained $500 \mathrm{mg}$ of ranolazine. The formulae for the preparation of tablets are presented in Table 2. All ingredients were collected and weighed accurately as per the formula. All were subjected to sifting to achieve good compression properties. After sifting, they were mixed in polya for obtaining uniform blend. The obtained blend was subjected to lubrication and processed for applying force to get desired tablet press. Resultant tablets were subjected to pharmaceutical product performance tests.

\section{Evaluation of ranolazine extended release tablets}

\section{Crushing strength}

It was determined using tablet hardness tester on the basis of diametric breakage of tablets.

\section{Friability}

This test was performed using a friability test apparatus (Roche). The selected number of tablets (20) were weighed accurately weight was noted $\left(W_{0}\right)$, tablets were subjected to rotations (25 rpm for $4 \mathrm{~min}$ ) again weight was noted (W). \% weight loss was determined using the following formula.

\section{Weight loss $(\%)=\left[\mathrm{W}_{0}-\mathrm{W} / \mathrm{W}_{0}\right] \times 100$}

\section{Drug content}

It was carried out as per the standard procedure, take 20 tablets and triturated to obtain fine powder, a quantity equivalent to $100 \mathrm{mg}$ of ranolazine was calculated and was dissolved in 0.1 $\mathrm{N} \mathrm{HCl}$. The sample was subjected to sonication and clarified by passing the solution via $0.45 \mu$ filter press. After preparing the aliquots, their absorbances were measured at $272 \mathrm{~nm}$ using ultraviolet-visible (UV) spectrophotometer.

\section{Thickness}

It was obtained using vernier calipers on the principal longitudinal basis.

\section{Drug dissolution}

This test was performed using USP tablet dissolution test apparatus (type 2) as per the standard conditions, such as 900 $\mathrm{mL}$ of $\mathrm{pH} 1.2$ buffer as the dissolution medium for the first 2 $\mathrm{h}$ followed by phosphate buffer $\mathrm{pH}$ 6.8. The temperature was maintained at $37 \pm 0.5^{\circ} \mathrm{C}$ and paddle was rotated at a rate of 50 revolutions per minute. The samples were collected as per the protocol and analyzed for drug release using spectrometry at $272 \mathrm{~nm}$. Analysis is done in triplicate manner. ${ }^{14}$

\section{Statistical analysis}

The data obtained were fit to kinetic modeling to ascertain the mechanism of drug release. The statistical parameters (a, b, r) were determined as kinetic parameters. ${ }^{20,21}$ The dissolution parameters were also determined using polynomial equations.

\section{RESULTS AND DISCUSSION}

$\mathrm{XR}$ tablets of ranolazine were developed as per 3-level, 2-factor design for optimizing the combination of drug release modifiers (Eudragit L 100-55, HPMC K100M). The formulation design is 
presented in Table 1. The quantity of Eudragit $L 100-55\left(X_{1}\right)$ and HPMC K100M $\left(X_{2}\right)$ chosen as factors and time for obtaining dissolution chosen as responses $\left(t_{10 \%}, t_{50 \%}, t_{75 \%}, t_{90 \%}\right)$. Nine trials were developed as per the formula given in Table 2 .

All trials have ranolazine $(500 \mathrm{mg}$ ) as an XR formulation, obtained as tablet using direct compression technique. The

Table 1. Experimental design layout

\begin{tabular}{lll} 
Formulation code & $\mathrm{X}_{1}$ & $\mathrm{X}_{2}$ \\
\hline $\mathrm{RF}_{1}$ & 1 & 1 \\
\hline $\mathrm{RF}_{2}$ & 1 & 0 \\
\hline $\mathrm{RF}_{3}$ & 1 & -1 \\
\hline $\mathrm{RF}_{4}$ & 0 & 1 \\
\hline $\mathrm{RF}_{5}$ & 0 & 0 \\
\hline $\mathrm{RF}_{6}$ & 0 & -1 \\
\hline $\mathrm{RF}_{7}$ & -1 & 1 \\
\hline $\mathrm{RF}_{8}$ & -1 & 0 \\
\hline $\mathrm{RF}_{9}$ & -1 & -1 \\
\hline $\mathrm{CR}_{1}$ & -0.5 & -0.5 \\
\hline $\mathrm{CR}_{2}$ & +0.5 & +0.5 \\
\hline
\end{tabular}

developed formulations were evaluated for pharmaceutical product performance tests. The data are presented in Table 3. All formulations have sufficient mechanical strength. All formulations found to be less friable, as within the limits. All batches passed the drug content uniformity test. All formulation batches passed the weight variation test. Dissolution rate test was carried as per standard procedure, the dissolution specifications such as $900 \mathrm{~mL}$ of simulated gastric fluid for the first $2 \mathrm{~h}$ followed by simulated intestinal fluid; paddle was rotated at a speed of $50 \mathrm{rpm}$, the temperature maintained as $37 \pm 0.5^{\circ} \mathrm{C}$ throughout the test period. The dissolution profile was well fit to kinetic modeling, results are presented in Table 4 and the same was presented as plots from Figure 1-4. From the results, observed that there was a clear relation existed between the quantities of polymers in combination with the drug release rate (both were inversely proportional to each other). Predicted sustained release of drug was obtained by appropriate composition of factors $\left(X_{1}, X_{2}\right)$.

Based on the desirability factor, $\mathrm{RF}_{5}$ is considered the best formulation among all batches. $\mathrm{RF}_{5}$ composed of both Eudragit L 100-55 and HPMC K100M in equal quantity i.e. 31.25 mg each, produced promising dissolution characteristics, which help in meeting the purpose of research by extended period of drug release (optimum delivery of drug) from dosage form.

Table 2. Formulae for ranolazine extended release tablets

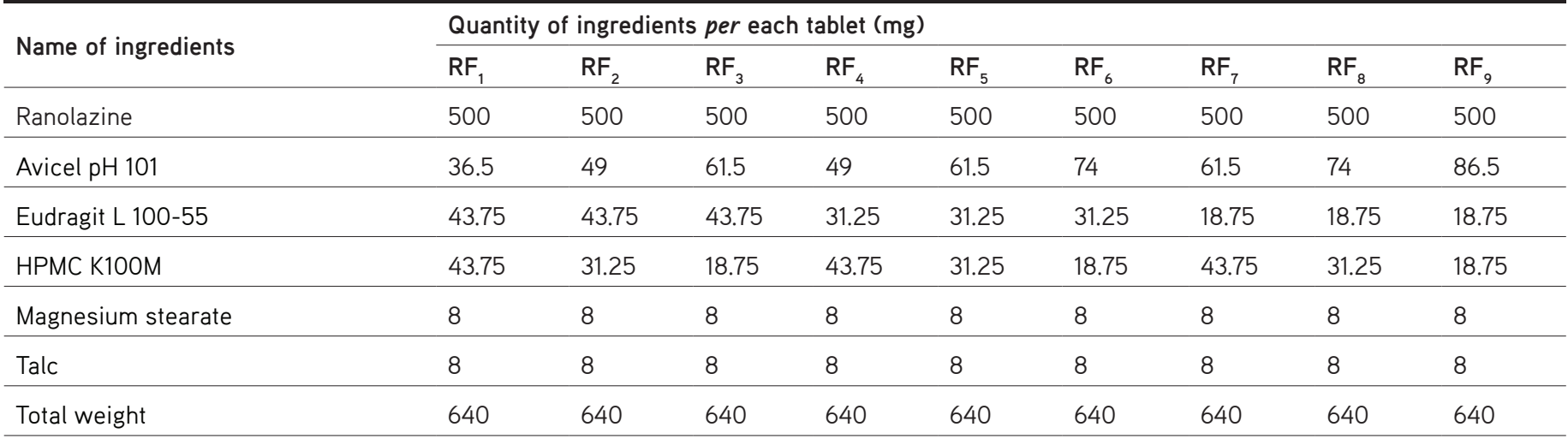

HPMC: Hydroxypropylmethylcellulose

Table 3. Post-compression parameters for the formulations $(n=3)$

\begin{tabular}{llllll} 
Batch code & Hardness $\left(\mathrm{kg} / \mathrm{cm}^{2}\right)$ & Thickness $(\mathrm{mm})$ & Friability (\%) & Average weight (mg) & Drug content (\%) \\
\hline $\mathrm{RF}_{1}$ & $8.47 \pm 0.27$ & $4.06 \pm 0.08$ & $0.10 \pm 0.001$ & $641.09 \pm 0.01$ & $99.94 \pm 0.49$ \\
\hline $\mathrm{RF}_{2}$ & $8.2 \pm 0.28$ & $3.98 \pm 0.085$ & $0.11 \pm 0.001$ & $641.11 \pm 0.01$ & $99.45 \pm 0.50$ \\
\hline $\mathrm{RF}_{3}$ & $7.93 \pm 0.27$ & $3.9 \pm 0.08$ & $0.09 \pm 0.001$ & $641.10 \pm 0.01$ & $99.11 \pm 0.51$ \\
\hline $\mathrm{RF}_{4}$ & $8.52 \pm 0.42$ & $4.1 \pm 0.06$ & $0.06 \pm 0.001$ & $641.14 \pm 0.02$ & $99.74 \pm 0.32$ \\
\hline $\mathrm{RF}_{5}$ & $8.10 \pm 0.41$ & $4.05 \pm 0.06$ & $0.07 \pm 0.001$ & $642.2 \pm 0.02$ & $99.43 \pm 0.33$ \\
\hline $\mathrm{RF}_{6}$ & $7.7 \pm 0.41$ & $3.99 \pm 0.05$ & $0.07 \pm 0.001$ & $641.31 \pm 0.02$ & $99.11 \pm 0.34$ \\
\hline $\mathrm{RF}_{7}$ & $8.35 \pm 0.42$ & $4.18 \pm 0.05$ & $0.05 \pm 0.001$ & $640.66 \pm 0.02$ & $99.70 \pm 0.43$ \\
\hline $\mathrm{RF}_{8}$ & $7.91 \pm 0.42$ & $4.05 \pm 0.06$ & $0.04 \pm 0.001$ & $641.2 \pm 0.01$ & $99.23 \pm 0.47$ \\
\hline $\mathrm{RF}_{9}$ & $7.49 \pm 0.41$ & $4.02 \pm 0.06$ & $0.05 \pm 0.001$ & $640.65 \pm 0.01$ & $98.77 \pm 0.35$ \\
\hline
\end{tabular}


Table 4. Regression analysis for factorial trials

\begin{tabular}{|c|c|c|c|c|c|c|c|c|c|c|c|c|}
\hline \multirow{3}{*}{ Formulation code } & \multicolumn{12}{|c|}{ Kinetic parameters } \\
\hline & \multicolumn{3}{|c|}{ Zero order } & \multicolumn{3}{|c|}{ First order } & \multicolumn{3}{|c|}{ Higuchi } & \multicolumn{3}{|c|}{ Korsmeyer-Peppas } \\
\hline & a & b & $r$ & a & $\mathrm{b}$ & $r$ & a & b & $r$ & a & $b$ & $r$ \\
\hline $\mathrm{RF}_{1}$ & 14.410 & 3.284 & 0.982 & 1.988 & 0.034 & 0.986 & 1.685 & 17.614 & 0.995 & 1.089 & 0.629 & 0.962 \\
\hline $\mathrm{RF}_{2}$ & 14.857 & 3.285 & 0.981 & 1.986 & 0.034 & 0.986 & 1.308 & 17.641 & 0.995 & 1.098 & 0.625 & 0.959 \\
\hline $\mathrm{RF}_{3}$ & 15.304 & 3.285 & 0.979 & 1.985 & 0.034 & 0.986 & 0.930 & 17.667 & 0.995 & 1.107 & 0.621 & 0.957 \\
\hline $\mathrm{RF}_{4}$ & 15.946 & 3.819 & 0.982 & 2.110 & 0.065 & 0.931 & 2.738 & 20.473 & 0.995 & 1.125 & 0.651 & 0.960 \\
\hline $\mathrm{RF}_{5}$ & 16.302 & 3.834 & 0.982 & 2.171 & 0.077 & 0.877 & 2.481 & 20.560 & 0.995 & 1.132 & 0.649 & 0.958 \\
\hline $\mathrm{RF}_{6}$ & 16.657 & 3.848 & 0.981 & 2.117 & 0.068 & 0.931 & 2.224 & 20.646 & 0.995 & 1.138 & 0.647 & 0.956 \\
\hline $\mathrm{RF}_{7}$ & 23.404 & 3.915 & 0.948 & 2.112 & 0.093 & 0.964 & 2.240 & 21.685 & 0.992 & 1.199 & 0.641 & 0.950 \\
\hline $\mathrm{RF}_{8}$ & 23.778 & 3.923 & 0.948 & 2.185 & 0.110 & 0.949 & 2.539 & 21.742 & 0.993 & 1.204 & 0.638 & 0.948 \\
\hline $\mathrm{RF}_{9}$ & 24.304 & 3.883 & 0.946 & 2.286 & 0.124 & 0.915 & 3.157 & 21.565 & 0.993 & 1.210 & 0.634 & 0.945 \\
\hline Marketed product & 17.313 & 3.884 & 0.979 & 2.201 & 0.086 & 0.897 & 1.910 & 20.897 & 0.995 & 1.148 & 0.644 & 0.955 \\
\hline
\end{tabular}

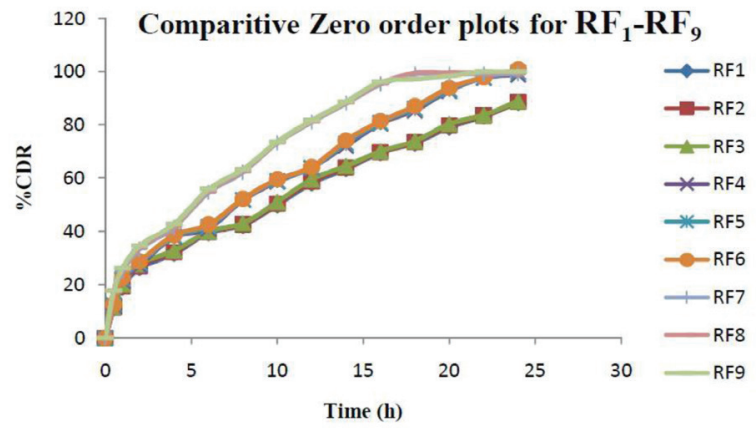

Figure 1. Comparative zero order plots

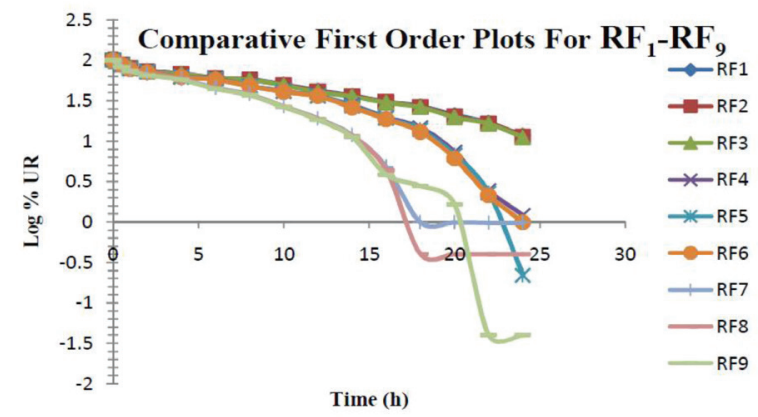

Figure 2. Comparative first order plots

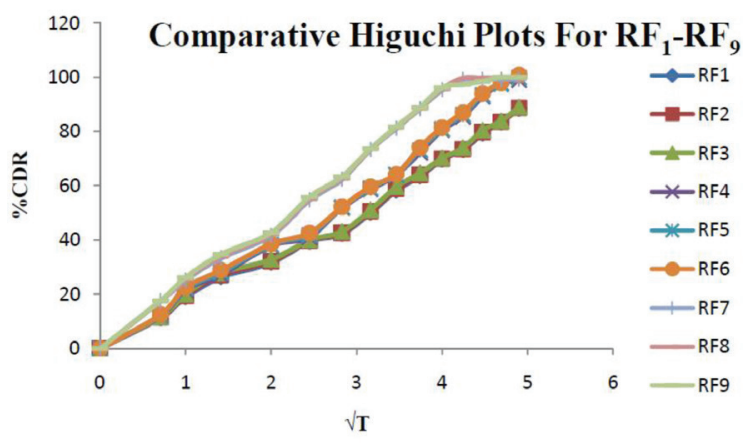

Figure 3. Comparative Higuchi plots

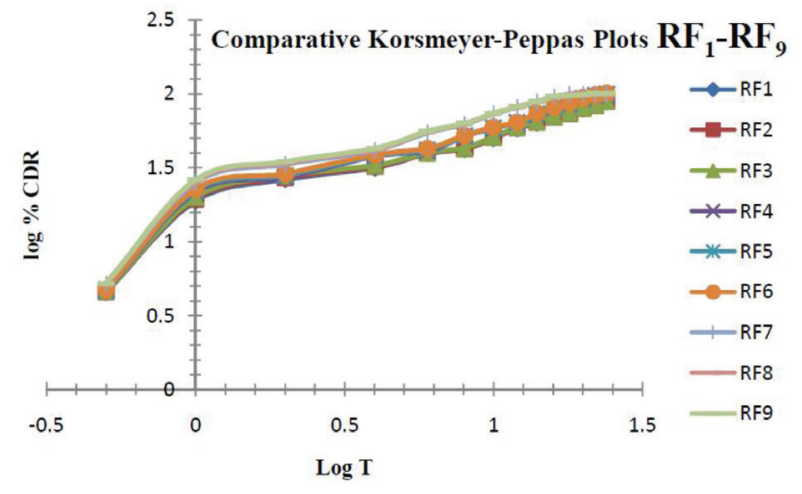

Figure 4. Comparative Korsmeyer-Peppas plots

Contour Graph for $\mathbf{1 1 0} \%$

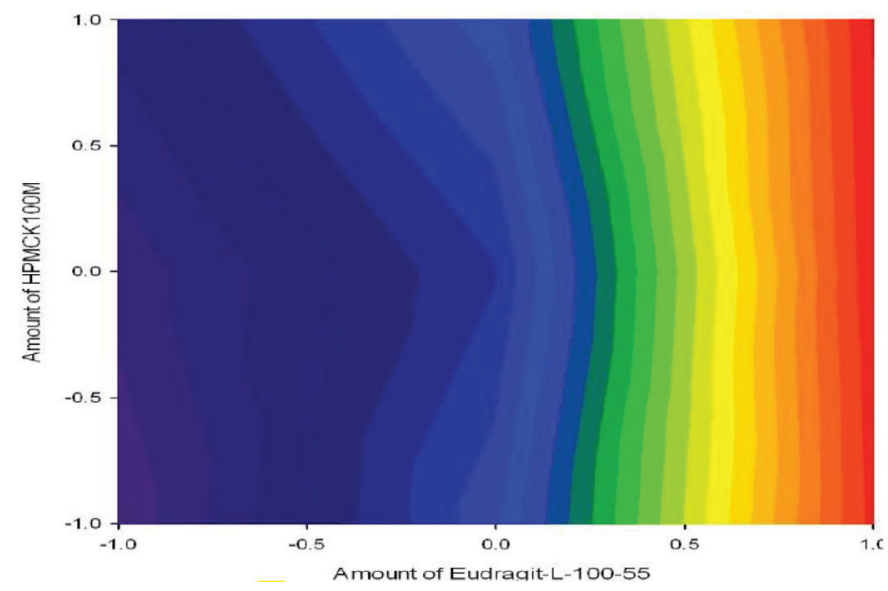

Figure 5. Contour plots for $t_{10 \%}$

RSM equations (polynomial) were derived for all responses using PCP Disso and RSM plots were obtained with the help of Design-Expert 7.0. The response morphological plots were presented as Figure 5-9. The dissolution parameters for $\mathrm{RF}_{1}$ $\mathrm{RF}_{\text {g }}$ were summarized as Table 5 . 
Contour Graph for $125 \%$

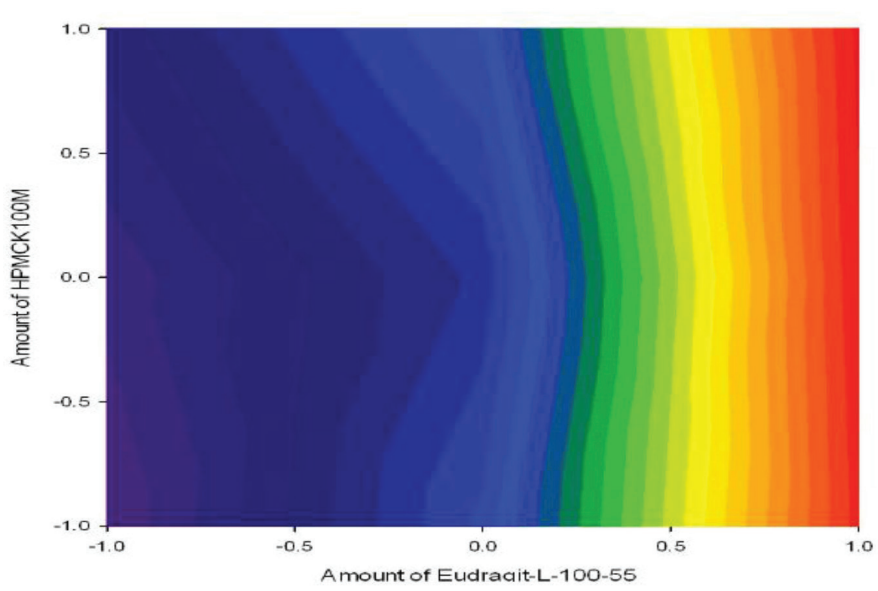

Figure 6. Contour plots for $\mathrm{t}_{25 \%}$

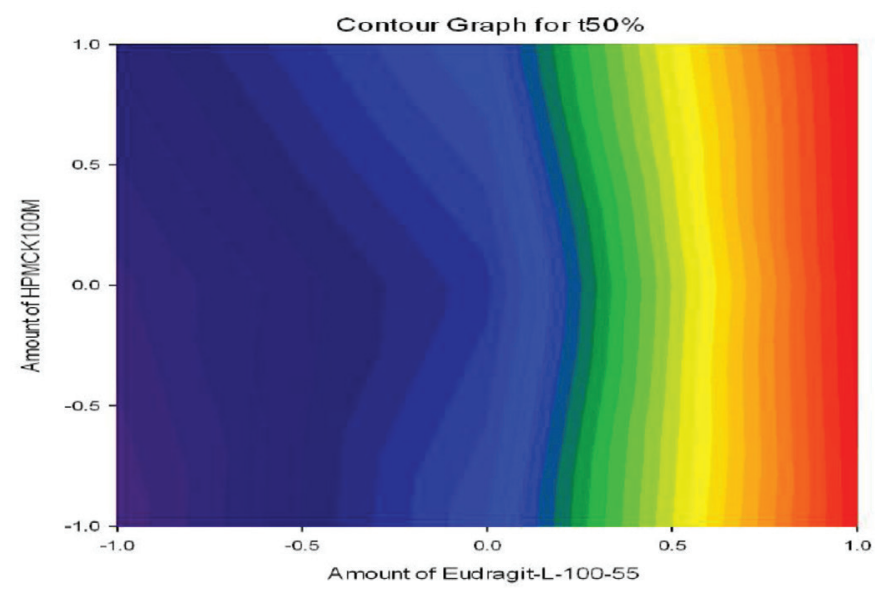

Figure 7. Contour plots for $t_{50 \%}$

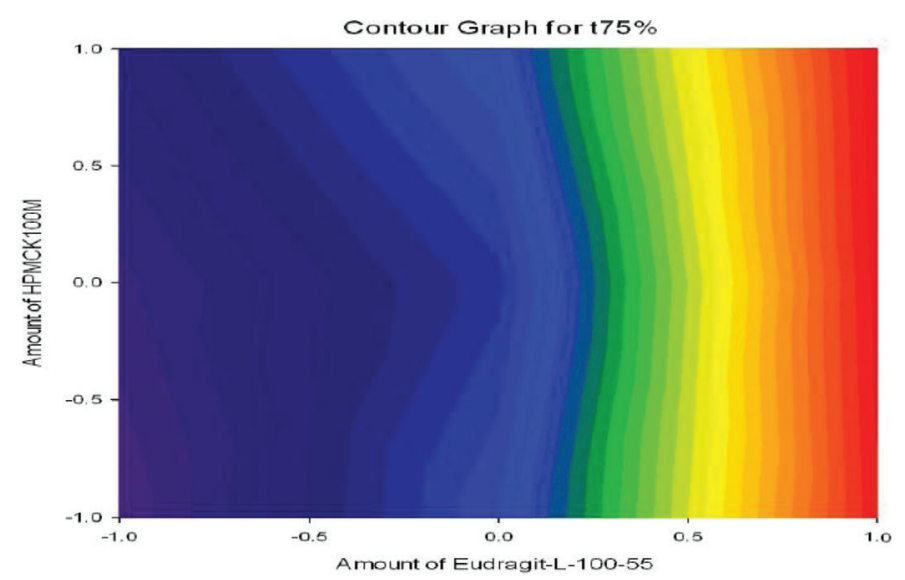

Figure 8. Contour plots for $t_{75 \%}$

RSM equations for the determination of predicted kinetic parameters as follows;

$Y_{1}=0.810+0.461 X_{1}+0.038 X_{2}-0.024 X_{1} X_{2}+0.232 X_{1}^{2}+0.035 X_{2}^{2}\left(t_{10 \%}\right)$ $Y_{2}=2.210+1.23 X_{1}+0.084 X_{2}-0.065 X_{1} X_{2}+0.632 X_{1}^{2}+0.096 X_{2}^{2}\left(t_{25 \%}\right)$

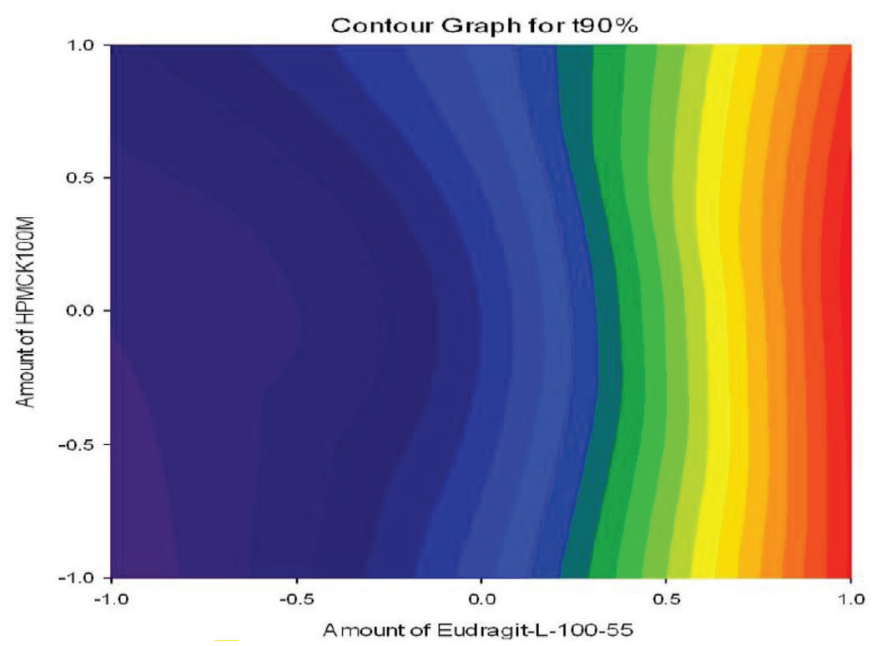

Figure 9. Contour plots for $t_{90 \%}$

\begin{tabular}{llllll} 
Table 5. Dissolution parameters for factorial formulations \\
\multirow{2}{*}{ Formulation code } & \multicolumn{6}{c}{ Dissolution parameters } \\
\cline { 2 - 6 } & $t_{10 \%}(h)$ & $t_{25 \%}(h)$ & $t_{1 / 2}(h)$ & $t_{75 \%}(h)$ & $t_{90 \%}(h)$ \\
\hline $\mathrm{RF}_{1}$ & 1.362 & 3.719 & 8.962 & 17.923 & 29.779 \\
\hline $\mathrm{RF}_{2}$ & 1.348 & 3.679 & 8.865 & 17.731 & 29.460 \\
\hline $\mathrm{RF}_{3}$ & 1.333 & 3.639 & 8.769 & 17.537 & 29.139 \\
\hline $\mathrm{RF}_{4}$ & 0.701 & 1.913 & 4.611 & 9.221 & 15.321 \\
\hline $\mathrm{RF}_{5}$ & 0.596 & 1.627 & 3.921 & 7.843 & 13.030 \\
\hline $\mathrm{RF}_{6}$ & 0.669 & 1.827 & 4.401 & 8.803 & 14.626 \\
\hline $\mathrm{RF}_{7}$ & 0.493 & 1.345 & 3.242 & 6.484 & 10.773 \\
\hline $\mathrm{RF}_{8}$ & 0.415 & 1.132 & 2.728 & 5.456 & 9.065 \\
\hline $\mathrm{RF}_{9}$ & 0.369 & 1.007 & 2.426 & 4.852 & 8.061 \\
\hline$M_{a}$ arketed product & 1.362 & 1.447 & 3.487 & 17.923 & 11.589 \\
\hline & & & & & \\
\hline
\end{tabular}

$Y_{3}=5.33+3.04 X_{1}+0.21 X_{2}-0.156 X_{1} X_{2}+1.52 X_{1}^{2}+0.23 X_{2}^{2}\left(t_{50 \%}\right)$

$Y_{4}=10.65+6.07 X_{1}+0.41 X_{2}-0.31 X_{1} X_{2}+3.04 X_{1}^{2}+0.46 X_{2}^{2}\left(t_{75 \%}\right)$ $Y_{5}=17.695+10.08 X_{1}+0.675 X_{2}-0.518 X_{1} X_{2} 5.05 X_{1}{ }^{2}+0.765 X_{2}{ }^{2}\left(t_{90 \%}\right)$

Results for the predicted responses vs actual responses are presented in Table 6. Not much deviation was observed in the predicted $v s$ actual responses. It indicates the validity of the developed equation. $\mathrm{RF}_{5}$ was considered as ideal, it shows similarity factor ( $f 2$ ) 85.78, difference factor ( $f 1) \mathrm{tcl}, \mathrm{t}_{\text {cal }}<0.05$ compared with the marketed product (RANEXA). Comparative dissolution plots for best formulation $\left(\mathrm{RF}_{5}\right)$ and marketed product are shown in Figure 10.

\section{CONCLUSION}

On the basis of the current study, the use of macromolecules (polymers) in combination had its own advantages of maintaining integrity and extended drug release form of the formulation. The combination of a partially neutralized $\mathrm{pH}$-dependent polymer and $\mathrm{pH}$-independent polymer at an appropriate proportion will yield desired extended drug release, 
Table 6. Dissolution parameters for check point formulations

\begin{tabular}{|c|c|c|c|c|c|c|c|c|c|c|}
\hline \multirow{2}{*}{ Formulation code } & \multicolumn{5}{|c|}{ Predicted value } & \multicolumn{5}{|c|}{ Actual observed value } \\
\hline & $t_{10 \%}(h)$ & $t_{25 \%}(h)$ & $t_{50 \%}(h)$ & $t_{75 \%}(h)$ & $t_{90 \%}(h)$ & $t_{10 \%}(h)$ & $t_{25 \%}(h)$ & $t_{50 \%}(h)$ & $t_{75 \%}(h)$ & $t_{90 \%}(h)$ \\
\hline $\mathrm{CR}_{1}$ & 0.624 & 1.704 & 4.106 & 8.22 & 13.643 & 0.62 & 1.69 & 4.31 & 8.19 & 13.71 \\
\hline $\mathrm{CR}_{2}$ & 1.116 & 3.047 & 7.342 & 14.684 & 24.397 & 1.12 & 3.11 & 7.54 & 14.55 & 23.99 \\
\hline
\end{tabular}

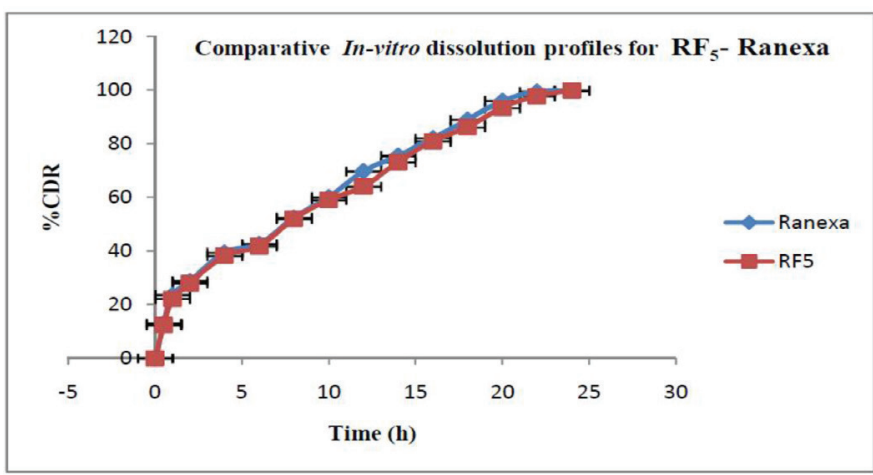

Figure 10. Comparative dissolution plots for RF5-Ranexa

which ultimately 2 -fold reduction in the dosing frequency of ranolazine. This is achieved by preparing the ranolazine with combination polymers like Eudragit L 100-55 and HPMC K100M employing along with other excipients using $3^{2}$ factorial design approaches. Among the various ER formulations studied, the formulation $\left(\mathrm{RF}_{5}\right)$ showed the best result in all aspects of objective, which was considered as the ideal formulation. The best formulation $\mathrm{RF}_{5}$ follows zero order release, non-fickian diffusion, it may improve patient compliance by reducing the dosing frequency to 2 fold or more, which will ultimately improve the clinical response.

\section{ACKNOWLEDGMENTS}

Authors acknowledge sincere thanks to the Management and Staff of M.A.M College of Pharmacy, India for the facilities granted and constant encouragement for completing current research investigation.

\section{Ethics}

Ethics Committee Approval: There is no requirement for ethical approval.

Informed Consent: Not applicable.

Peer-review: Externally peer-reviewed.

\section{Authorship Contributions}

Concept: R.K.G., D.D., Design: K.R.G., Data Collection or Processing: R.K.G., Analysis or Interpretation: P.R.M., D.D., Literature Search: R.K.G., Writing: R.K.G., K.R.G.

Conflict of Interest: No conflict of interest was declared by the authors.

Financial Disclosure: The authors declared that this study received no financial support.

\section{REFERENCES}

1. Remington. The science and practice of pharmacy. (21 $1^{\text {st }}$ ed). USA; Lippincott, Williams and Wilkins Publications; 2005:939-964.

2. Tegk M, Mukkala BVP, Babu VV S. Formulation and evaluation of ranolazine extended release tablets: influence of polymers. Asian $\mathrm{J}$ Pharm. 2011;5:162-166.

3. Adepu H, Srilatha S, Reddy MR. Formulation and evaluation of film coated ranolazine extended release tablets. Int J Inn Pharm Sci Res. 2014:2:2283-2294.

4. Uddin NM, Ahmed I, Roni MA, Islam MR, Rahman MH, UI Jalil R. In vitro release kinetics study of ranolazine from swellable hydrophilic matrix tablets. Dhaka Univ J Pharm Sci. 2009;8:31-38.

5. Gunda RK, Vijayalakshmi A. Formulation development and evaluation of gastro retentive bioadhesive drug delivery system for moxifloxacin. HCl. Ind J Pharm Edu Res. 2019;53:724-732.

6. Jitendra G, Govind M, Prabakaran L, Reena G. Formulation development and characterization of modified release microspheres of antianginal. Drug Int J Drug Dev Res. 2014;6:252-265.

7. Bawankar DL, Deshmane SV, More SM, Channawar MA, Chandewar AV, Shreekanth J. Design and characterization of extended release ranolazine matrix tablet. Res J Pharm Tech. 2009;2:756-761.

8. Kumar CB, Aparna C, Srinivas P. Formulation and evaluation of solid self emulsifying drug delivery sytem of ranolazine. J Glob Tren Pharm Sci. 2014;5:2238-2247.

9. Bidada J, Gonjari I, Bhusari A, Raut C. Dhule A. Development of extended release matrix tablets of ranolazine containing polyacrylic and ethylcellulose polymers. Der Pharm Let. 2011;3:215-226.

10. Kuchekar SB, Mohite SK. Design and evaluation of extended release ranolazine liquisoloid tablets using placket burman screening design. Asian J Pharm Clin Res. 2015;8:292-300.

11. Rahman M, Hasan S, Alam A, Roy S, Kumar Jha M, Ahsan Q, Rahman $\mathrm{H}$. Formulation and evaluation of ranolazine sustained release matrix tablets using Eudragit and HPMC. Int J Pharm Biomed Res. 2011;1:172177.

12. Pittala B, Bommagani NK, Vasudeva Murthy S, Basani M, Nagavalli P. Formulation and evaluation of ranolazine extended release tablets by using $\mathrm{pH}$ dependent and independent polymers. Int J Pharm Bio Arc. 2013;4:1164-1171.

13. Asaduzzaman, Rahman R, Khan SR, Islam SMA. Development of sustain release matrix tablet of ranolazine based on methocel K4M CR: in vitro drug release and kinetic approach. J App Pharm Sci. 2011;1:131-136.

14. Priya MR, Natarajan R, Rajendran NN. Design and in vitro evaluation of sustained release tablets of ranolazine. Int J Pharm Sci Res. 2011;2:922-928.

15. Gunda RK. Formulation development and evaluation of rosiglitazone maleate sustained release tablets using $3^{2}$ factorial design. Int J Pharm Tech Res. 2015;8:713-724. 
16. Gunda RK, Manchineni PR. Statistical design and optimization of sustained release formulations of pravastatin. Turk J Pharm Sci. 2020;17:221-227.

17. Kumar GR, Vijayalakshmi A. Formulation and evaluation of gastro retentive floating drug delivery system for novel fluoroquinolone using natural and semisynthetic polymers. Iran J Pharm Sci. 2020;16:49-60.

18. Gunda RK, Vijayalakshmi A. Development and evaluation of gastroretentive formulations for moxifloxacin. hydrochloride. Thai J Pharm Sci. 2020;44:30-39.
19. Gunda Kumar R, Kumar JNS. Formulation development and evaluation of doxofylline sustained release tablets. FABAD J Pharm Sci. 2017;42:199-208.

20. Babu AK, Ramana MV. In vitro and in vivo evaluation of quetiapine fumarate controlled gastroretentive floating drug delivery system. Int J Drug Del. 2016;8:12-22.

21. Ramana M, Babu A, Thadanki M. Formulation development and evaluation of omeprazole microspheres by using the $\mathrm{pH}$ sensitive enteric polymers. The FASEB Journal, 28: LB590. doi.org/10.1096/ fasebj.28.1_supplement.lb590 